\title{
A multidimensional view on social and non-social rewards
}

Article

Published Version

Creative Commons: Attribution 4.0 (CC-BY)

Open Access

Matyjek, M., Meliss, S., Dziobek, I. and Murayama, K. (2020) A multidimensional view on social and non-social rewards.

Frontiers in Psychiatry, 11. 818. ISSN 1664-0640 doi: https://doi.org/10.3389/fpsyt.2020.00818 Available at https://centaur.reading.ac.uk/95602/

It is advisable to refer to the publisher's version if you intend to cite from the work. See Guidance on citing.

To link to this article DOI: http://dx.doi.org/10.3389/fpsyt.2020.00818

Publisher: Frontiers

All outputs in CentAUR are protected by Intellectual Property Rights law, including copyright law. Copyright and IPR is retained by the creators or other copyright holders. Terms and conditions for use of this material are defined in the End User Agreement.

\section{www.reading.ac.uk/centaur}

\section{CentAUR}

Central Archive at the University of Reading

Reading's research outputs online 


\section{OPEN ACCESS}

Edited by:

Anna-Lena Zietlow,

Universität Mannheim, Germany

Reviewed by:

Daniela M. Pfabigan,

University of Oslo, Norway

Chantal Martin Soelch,

Université de Fribourg, Switzerland

${ }^{*}$ Correspondence:

Magdalena Matyjek

magdalena.matyjek@hu-berlin.de Stefanie Meliss

stefanie.meliss@pgr.reading.ac.uk

${ }^{\dagger}$ These authors share first authorship

${ }^{\ddagger}$ These authors share senior authorship

Specialty section:

This article was submitted to Social Cognition,

a section of the journal

Frontiers in Psychiatry

Received: 24 March 2020

Accepted: 29 July 2020

Published: 19 August 2020

Citation:

Matyjek M, Meliss S, Dziobek I and

Murayama K (2020) A

Multidimensional View on Social and

Non-Social Rewards.

Front. Psychiatry 11:818.

doi: 10.3389/fpsyt.2020.00818

\section{A Multidimensional View on Social and Non-Social Rewards}

\author{
Magdalena Matyjek ${ }^{1,2 * t}$, Stefanie Meliss ${ }^{3 * \dagger}$, Isabel Dziobek ${ }^{1,2 \ddagger}$ and Kou Murayama ${ }^{3,4 \neq}$ \\ ${ }^{1}$ Berlin School of Mind and Brain, Humboldt-Universität zu Berlin, Berlin, Germany, ${ }^{2}$ Department of Psychology, Humboldt- \\ Universität zu Berlin, Berlin, Germany, ${ }^{3}$ School of Psychology and Clinical Language Sciences, University of Reading, \\ Reading, United Kingdom, ${ }^{4}$ Research Institute, Kochi University of Technology, Kochi, Japan
}

Social rewards are a broad and heterogeneous set of stimuli including for instance smiling faces, gestures, or praise. They have been widely investigated in cognitive and social neuroscience as well as psychology. Research often contrasts the neural processing of social rewards with non-social ones, with the aim to demonstrate the privileged and unique nature of social rewards or to examine shared neural processing underlying them. However, such comparisons mostly neglect other important dimensions of rewards that are conflated in those types of rewards: primacy, temporal proximity, duration, familiarity, source, tangibility, naturalness, and magnitude. We identify how commonly used rewards in both social and non-social domains may differ in respect to these dimensions and how their interaction calls for careful consideration of alternative interpretations of observed effects. Additionally, we propose potential solutions on how to adapt the multidimensional view to experimental research. Altogether, these methodological considerations aim to inform and improve future experimental designs in research utilizing rewarding stimuli, especially in the social domain.

Keywords: social reward, non-social reward, reward dimension, primacy, tangibility, familiarity, reinforcement learning

\section{SOCIAL AND NON-SOCIAL REWARDS}

Rewards are desired, appetitive, and positive outcomes of motivated behavior that can increase and maintain the frequency and strength of the behavior they are contingent on (1). They often serve as reinforcers, i.e. positive (or in other cases negative) stimuli or events that actually change the probability of that behavior's occurrence or its strength in the future (2). Because humans do not live in isolation, many rewarding experiences stem from social interaction and relationships. Social rewards are a broad set of stimuli, which instigate positive experiences involving other people, including a vast repertoire of verbal and non-verbal behaviors, gestures, and feelings (3) such as a smile (4), praise (5), a thumbs-up (6), acquisition of good reputation (7), etc. However, despite the considerable heterogeneity of social rewards and abundance of research utilizing them, it is not clear what constitutes rewards as social and there has been surprisingly little systematic discussion on how we can conceptualize them. Nevertheless, regardless of lacking a clear definition of social rewards, there is a large body of literature discussing them in relation to non-social ones.

Social rewards have been studied by two different lines of research. The first line of research aims to address the "privileged" nature of social rewards, arguing that there are dedicated, special 
mechanisms that subserve social functioning, including social rewards. These studies often contrast them against non-social rewards to demonstrate if and how they are processed differently from non-social environmental rewards. For example, autism, which is characterized by pervasive social impairments (8), has been taken as an example of atypical responsiveness to social cues. Researchers have hypothesized impaired processing of social, and preserved processing of non-social rewards [social motivation hypothesis; Chevallier et al. (9)] and have been testing this prediction by comparing responses to social and non-social rewards [for a review, see Bottini (10)]. The comparison is also common in other fields with non-clinical populations [e.g., Kohls et al. (11)].

Another line of research has indicated that social and nonsocial rewards may be processed in a similar manner. This is supported by economic theories proposing that behaviors stem from the desire to maximize the ratio of rewards to costs (12) and this applies to non-social as well as to social rewards [social exchange theory, Thibaut and Kelley (13)]. Indeed, many studies investigating the neural basis of reward processing found that social and non-social rewards are processed in the same brain areas of what is referred to as the reward network [i.e. a corticobasal ganglia circuit, Haber and Knutson (14)], especially in the striatum, supporting the assumption of an "extended common currency schema" (15). However, researchers have also emphasized specific activity differences in line with the idea of "social-valuation-specific schema" (15), which assumes dedicated brain circuits for social rewards. For instance, a study comparing the rewarding properties of receiving money or positive social feedback found that both rewards activated the striatum, especially the left nucleus caudate, and that this region also showed a linear activity increase towards both reward values (7). A reanalysis of the same data using machine learning, however, yielded a fairly small correlation between classifier weights for social and monetary rewards, suggesting that only a subset of neurons in the caudate nucleus encodes both rewards, whereas also distinct populations of neurons are involved for social and for non-social rewards separately (16). Thus, although both types of rewards can be processed in similar structures of the reward network in the brain [e.g. Izuma et al. (7); Spreckelmeyer et al. (4); Wake and Izuma (16)]; Smith et al. (17); Levy and Glimcher (18); Lin et al. (19), there has also been accumulating evidence for differences in neural processing between social and non-social rewards [e.g. Izuma et al. (7); Smith et al. (17); Sescousse et al. (20); for a recent review of literature discussing overlaps and differences in neural processing of social and non-social rewards, see Ruff and Fehr (15)].

These studies suggest that there are both similarities and differences in neural processing between social and non-social rewards. However, we argue that research comparing social and non-social rewards often neglects important dimensions that can be conflated with the sociality dimension. For example, comparing brain responses to receiving a smile or money may potentially reveal a difference between social and non-social rewards as well as between intangible and tangible rewards. In this article, we propose a more comprehensive, multidimensional view on rewards in experimental settings, which allows more informed and better-controlled comparisons of social and nonsocial rewards.

\section{DIMENSIONS OF REWARDING STIMULI}

Research contrasting social and non-social rewards implicitly assumes a binary categorization of those rewards. However, monetary reward is considered as non-social, but money could be regarded as a "social construct" in the sense that it would not exist without society and a collective agreement of their function [social constructionism, e.g. Galbin (21)]. Thus, binary categorization of social and non-social may be an oversimplification, and a continuous dimension may provide a more accurate conceptualization. Moreover, we suggest that there are other dimensions to describe rewards, e.g. tangibility and primacy, and that considering them can offer alternative interpretations of observed differences between social vs. non-social rewards. This section describes these dimensions of rewarding stimuli (see Figure $\mathbf{1}$ for an overview). Our goal is not to provide a complete list of all possible dimensions, but to outline the scope of this multidimensional view with several examples, which we consider particularly relevant for social vs. nonsocial reward processing: primacy, temporal proximity, duration, familiarity, source, tangibility, naturalness, and magnitude. Importantly, we discuss how each of these dimensions interacts and confounds with social vs. non-social dimension.

\section{Primacy}

Primacy is a dimension categorizing rewards [after theories of operant conditioning, Skinner (22)] depending on whether they stem from innate or biologically pre-programmed reinforcing states (hunger satisfied by food or mother's closeness satisfying the need for touch of an infant) on one hand (i.e. primary rewards), or having rewarding properties through learned or acquired associations with primary reinforcers (money as a means to acquire food, a Facebook thumbs-up to gain social appreciation) on the other hand [i.e. secondary rewards; Delgado et al. (23)]. Thus, primary and secondary rewards can be found in both, social (touch, thumbs-up) and non-social (food, money) domain. Studies have shown that even though there is a partial overlap in the ventromedial prefrontal cortex (vmPFC) representing the anticipatory value of primary and secondary rewards $(18,24)$, there is also additional activity specific to primary (i.e. hypothalamic regions) and secondary rewards [i.e. posterior cingulate cortex; Levy and Glimcher (18)], respectively. Since primacy can be linked to distinct neural processing, it is important to choose rewards of the same primacy nature when comparing social and non-social ones.

\section{Temporal Proximity}

Temporal proximity describes the temporal relationship between motivated behavior and reward reception (e.g., immediate vs. delayed). There is evidence that they are processed distinctly in the human brain [e.g., Ballard and Knutson (25); for a review, see 

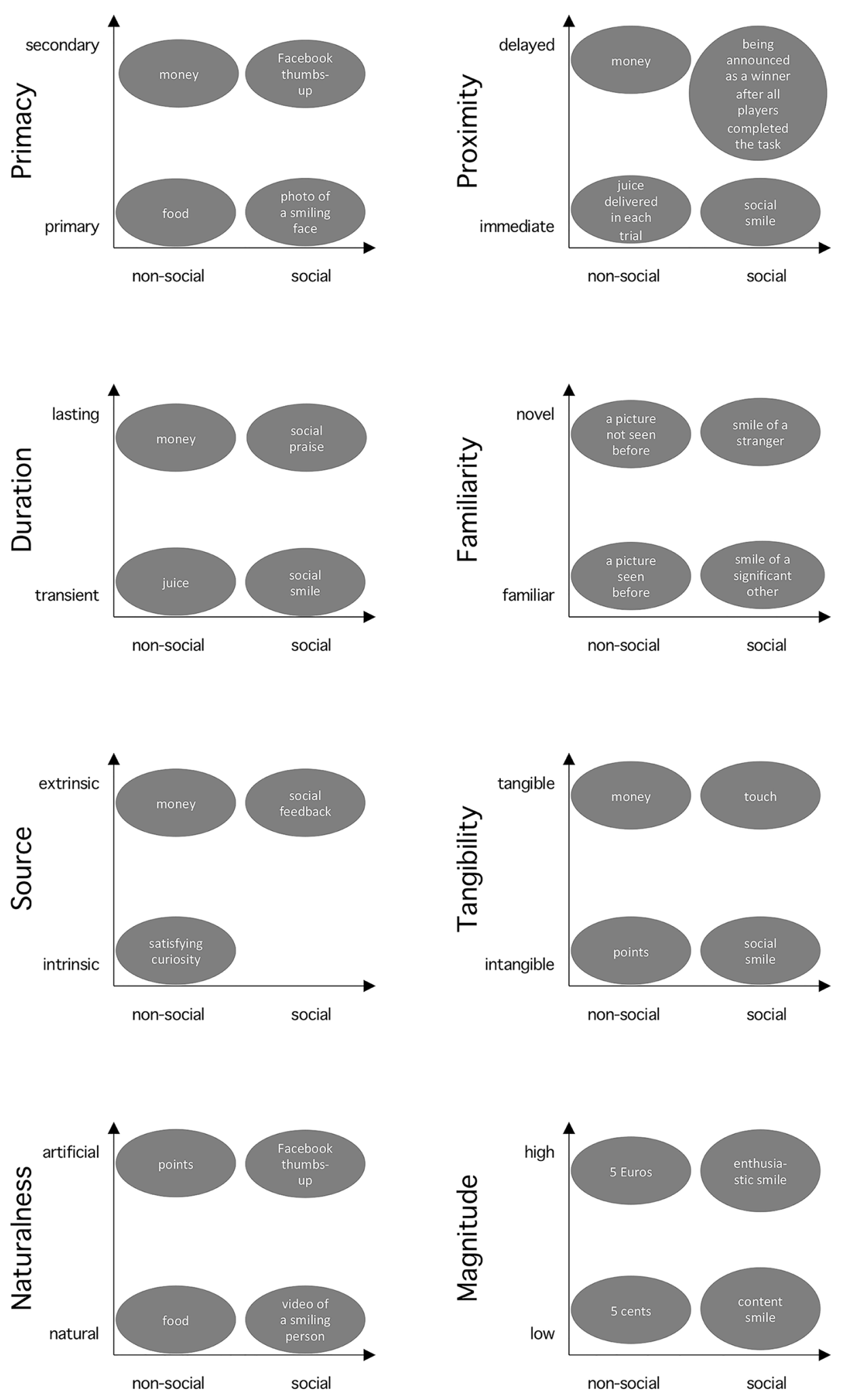

FIGURE 1 | Interplay of the sociality and other reward dimensions. The x-axis represents the sociality dimension. The provided cases illustrate examples of rewards used in psychology and neuroscience placed along the dimensions discussed in this article. The spatial distance between the cases does not directly depict differences in their rewarding value. 
Bermudez and Schultz (26)]. Specifically, midbrain, striatum, frontal cortex, and amygdala are all sensitive to time of reward occurrence (soon or later). Moreover, temporal discounting may lead to a preference for sooner smaller compared to later larger rewards. Social rewards are usually delivered immediately at the end of the trial in the form of a smile or social feedback, aligning simultaneous reception and consumption of reward. However, in the non-social domain, there is often a difference between reward reception in an experimental trial (e.g. a picture of a coin) and the actual consumption of the reward after the experiment (i.e., receiving the physical money). Note that sometimes the amount of points won in trials is not even directly translated to actual money gains (27). Thus, comparing social rewards with nonsocial rewards may trigger brain responses reflecting differences in the temporal proximity dimension in addition to the sociality dimension.

\section{Duration}

The dimension of duration distinguishes between lasting and transient rewards. Unlike transient rewards (consumed/ appreciated while presented), lasting ones may entail accumulation over time, which affects economic decision making and activity in vmPFC (28). While social ones most often are transient (a smile lasts only while presented, but praise may have longer-lasting effects generating feelings of appreciation), non-social rewards are more dependent on the experimental context. For example, money received in a task is still available after the end of the experiment, whereas juice delivered on a trial-by-trial basis is immediately consumed. Thus, when comparing social and non-social rewards, duration needs to be considered to avoid confoundedness.

\section{Familiarity}

Familiarity differentiates novel from familiar stimuli and is signaled in the striatum and the midbrain (29). While novelty is rewarding in non-social stimuli (29), it may be the opposite in the social domain, where familiar and socially relevant faces are more rewarding than faces of strangers (30). In fact, it has been shown that familiar faces are processed differently than faces of unknown people, due to different visual representations stored in memory, personal knowledge, and personal relevance (31). Furthermore, "familiarity" in the context of social rewards has multi-faceted meanings and there may be qualitative differences between familiarity with relatives, celebrities, and experimentally learned individuals (31), which can potentially lead to inconsistencies through differential engagement in experimental tasks (32). Altogether, familiarity may modulate social and non-social rewards differently, which should be considered in study designs.

\section{Source}

Source relates to whether the rewarding nature originates internally (i.e. intrinsically within a person, e.g. feeling curious) or externally (i.e. extrinsically by receiving food or praise). While psychological theories consider them as distinct [e.g., Deci and Ryan (33)], neuroscientific studies show that rewards from both sources activate the reward network (34), with additional brain regions specific for intrinsic rewards [the anterior insula; Lee (35)]. This can be a potential confound for the sociality dimension, as non-social rewards could stem from both sources (satisfying curiosity or receiving money), but social rewards are by definition extrinsic as provided by others (e.g. social feedback).

\section{Tangibility}

Tangibility refers to the property of a stimulus to be touched or consumed, with more abstract stimuli being less tangible. Studies suggest differential reinforcing and motivating effects of tangible and intangible stimuli (36), often via differential engagement of intrinsic and extrinsic motivation (37). For example, in a study with tangible monetary and intangible verbal rewards on intrinsic motivation, only the latter showed positive and prolonged effects (38). Because social rewards are most often intangible (like verbal praise) and non-social rewards are tangible (e.g. money), the interaction of sociality and tangibility is a potential confound.

\section{Naturalness}

Some studies use natural stimuli such as chocolate (18) or verbal praise (39) as rewards, whereas other studies use more arbitrary, symbolic stimuli such as Facebook thumbs-up icon (6) or a picture of a coin (11). Naturalness is especially important for social rewards. For example, there is an increasing number of studies using avatars [e.g. Kim et al. (40)] and cartoon representations of faces [e.g. Gonzalez-Gadea et al. (41)], which convey the social nature through the resemblance to their natural equivalences (faces). In fact, computer-generated and natural faces have been shown to elicit similar emotional processing in the amygdala, but also differential activation in the fusiform face area (42). Again, the interaction of sociality and this dimension should be considered and controlled for by choosing both social and non-social rewards to be either natural or representational.

\section{Magnitude}

The magnitude of a reward can be defined as the extent of its objective and subjective value. Studies have shown that activity in the ventral striatum correlates with the objective magnitude of both monetary [increasing amounts; Knutson et al. (43)] and social rewards [happy face expressions with increasing intensity level; Spreckelmeyer et al. (4)], and vmPFC correlates with the subjective magnitude of rewards (19). Critically, rewards with higher magnitude are likely to elicit larger responses in wider areas of the brain in comparison to rewards with lower magnitude [e.g. Smith et al. (44); Diekhof et al. (45)]. Differences in magnitude between rewards should thus be avoided to allow interpretation of the observed effects in terms of social vs. non-social (and not low vs. high magnitude).

In addition to the dimensions above, some other aspects contrast social rewards against other rewards. For example, social stimuli are usually complex and can be more ambiguous than non-social ones: The same smile may be interpreted as a friendly reaction or as a ridicule, depending on the context. Thus, it is important to take into account biases in the interpretation of ambiguous social stimuli linked to internal states [e.g. negativity 
bias in depressive states; Dai et al. (46)]. Also, psychological traits and conditions [like autistic traits and social anxiety; Cox et al. (47) and Cremers et al. (48), respectively] have been shown to modulate responses to social rewards specifically. Likewise, visual complexity may introduce altered processing: Non-social rewards are often less visually complex than their social counterparts $(6,49)$, introducing a perceptual bias and neural differences (50). Furthermore, it may be more challenging to uniformly induce a rewarding value of social stimuli than of nonsocial ones, as the rewarding value of social stimuli depends on a certain context around participant and reward. In fact, a smiling face seen on the screen can be rewarding for a participant performing a task only when they believe to some extent that this smile is contingent on their action, as it happens in natural interactions. Simply instructing participants that a smiling face indicates positive feedback might not make it sufficiently socially rewarding; this requires a perceived social context between the participant and the person on the screen, entailing that "social interaction must not inherently be rewarding due to the appearance of positive social stimuli" [Krach et al. (51), p.1]. Although some studies suggest that bottom-up processes are involved in the privileged processing of social stimuli (52), for a stimulus to be socially rewarding, it is not enough to be a representation of human likeness/gesture carrying positive feedback. Social rewards require the component of intention and direction from the observer to the observed, even if there is no direct (face-to-face) interaction between those two. In fact, one could consider social rewards that are delivered without a social visual stimulus. For example, in Kujawa et al. (53) participants saw a green checkmark (abstract symbol) as signifying social acceptance, a salient social reward (54). This is especially important considering recent attempts to bring experimental research closer to reality, which includes the use of dynamic stimuli $(55,56)$ and implementing a second-person approach in (neuroscientific) research on social cognition (57). Although instantiating social context may come at the cost of losing experimental control, some promising designs aiming to ensure ecological validity and experimental control have been proposed [e.g. Drimalla et al. (58)].

\section{IMPLICATIONS OF THE MULTIDIMENSIONAL VIEW ON REWARDING STIMULI IN EXPERIMENTAL DESIGNS}

As discussed, rewards can be described on multiple dimensions and each of them can be linked to different neural correlates and psychological processes. Thus, research interested in comparing social against non-social rewards should carefully control for other dimensions that may conflate the dimension of interest instead of ascribing the observed effects to a single one, like sociality. However, research has rarely considered these additional aspects of rewards [but see the discussion of primacy and tangibility of money and juice, Kim et al. (24); or praise, Wake and Izuma (16)]. For example, many studies simply compare smiling faces and monetary outcomes to examine the differences of social vs. nonsocial processing (59-62). However, both outcomes differ not only on the social - non-social dimension, but also in terms of their 1) tangibility: a smile is not tangible, but money as a reward in the form of coins and notes is; 2) primacy: a smile is a primary reward ${ }^{1}$, money is secondary; 3 ) proximity and duration: a smile is immediate and transient (its rewarding value lasts as long as its exposure), whereas money is lasting and distant, as it will be delivered at the end of the experiment. Hence, from this multidimensional perspective observed differences between responses to smiles and money cannot be fully ascribed to the social vs. non-social contrast but could also stem from differences in tangibility, primacy, proximity, and duration.

How can empirical research overcome these potential limitations? One strategy is to incorporate these dimensions as additional factors in an experimental design [e.g. visual complexity in Pfabigan et al. (50)]. However, this exponentially increases the number of conditions, which substantially boosts the length of the experiment and/or required sample size. An alternative solution is to use stimuli that match in other dimensions than sociality as much as possible. Previous research has shown that pleasant odors can engage the reward circuits $(64,65,66)$ which could be used in a comparison with social rewards like smiling faces. Both rewards would be balanced in terms of temporal proximity (both immediate), tangibility (both intangible), source (both external), and they can be matched with respect to their primacy, duration, familiarity, naturalness, and magnitude. Another approach could be to condition social and non-social rewards with neutral stimuli. For instance, Lehner et al. (67) matched reward magnitude of chocolate, money, and social smile with thumps-up using a willingness-to-pay paradigm and later paired them with neutral stimuli (matched in color, luminance, and complexity) to then measure the response to those stimuli. Finally, another potential solution would be to assess other dimensions as much as possible (e.g. using subjective ratings) and statistically control for these effects in the analysis. This strategy can also address potential individual differences in the interpretation of social stimuli.

Another implication of this multidimensional view is noteworthy for one of the most widely-used paradigms that compare social and non-social rewards: Monetary [MID; Knutson et al. $(43,68)$ ] and Social [SID; Spreckelmeyer et al. (4)] Incentive Delay tasks. In these tasks, participants are presented with a cue indicating possible outcomes in a given trial: a gain or loss, or no outcome (control condition). After a variable anticipation delay, they perform a task after which feedback (i.e. the amount of reward or punishment) is delivered depending on participants' performance. An advantage of the incentive delay paradigm is that it allows targeting both reward anticipation triggered by an incentive cue indicating a possible future reward, and reward reception, elicited with a rewarding stimulus after task performance $(43,68)$. It has been shown that both phases (anticipation and reception) involve different brain regions and they are modulated differently by the domain of rewards (social and non-social), with reception being more

${ }^{1}$ In this article, we consider smile as a primary reward as suggested by infants' preference for smiling faces (63), but other interpretations are possible. 
domain-specific than anticipation (69). This paradigm has intuitive appeal to contrast social and non-social rewards, but our multidimensional view suggests the potential difficulty in interpreting the results in terms of anticipation and reception, especially in the context of comparing social and nonsocial rewards.

For example, Kohls et al. (59) used a picture of a smiling face as both incentive cues and rewards in the SID task. However, a smile is an immediate reward (participants are being smiled at the moment), which entails that as an incentive cue it triggers not only anticipation as intended, but also reception of this reward. Moreover, in the MID task, a picture of a coin is normally presented as a signal that the trial was successful and thus participants receive a monetary reward. However, in reality, participants receive physical money at the end of the experiment, not immediately after each trial (money is a distant reward in such settings). Hence, a picture of a coin intended to represent a reception of reward may actually trigger another anticipation. In other words, when considering the dimension of temporal proximity, for both cases, the distinction between the reward processing phases becomes rather arbitrary. Confounding these two factors (reward processing phases and domain) has serious consequences on how we should interpret the results because both phases are associated with distinct brain areas (70). Disentangling of those factors could be achieved by using neutral, non-rewarding incentive cues to trigger anticipation [e.g. Matyjek et al. (71)], or by matching social and non-social rewards on the temporal proximity dimension (i.e. immediate vs. delayed rewards). For instance, to match social rewards, which are often immediate (e.g. a smile), their non-social counterparts can be delivered on a trial-by-trial basis, e.g. in form of juice (24) or direct online bank transfers. Similarly, to match non-social rewards, which have often delayed reception (e.g. money), the social condition could include trial-by-trial symbolic indications of positive feedback, which translate into social appreciation at the end of the experiment in a form of positive adjectives describing the participant (7), given by an "observer".

At a broader level, one important implication of the proposed multidimensional perspective is that it highlights a more nuanced relationship between social and non-social rewards than what researchers have previously assumed. As indicated earlier, while many studies seek neural correlates specialized to

\section{REFERENCES}

1. Schultz W. Neuronal reward and decision signals: From theories to data. Physiol Rev (2015) 95:853-951. doi: 10.1152/physrev.00023.2014

2. Tobler PN, Kobayashi S. Electrophysiological correlates of reward processing in dopamine neurons. In: Dreher JC, Tremblay L, editors. Handbook of Reward and Decision Making. Academic Press, Cambridge, MA. (2009) p. 29-50. doi: 10.1016/ B978-0-12-374620-7.00002-9

3. Bhanji JP, Delgado MR. The social brain and reward: Social information processing in the human striatum. In: Interdisciplinary Reviews: Cognitive Science. Vol. 5, no. 1. John Wiley and Sons, Ltd. (2014). p. 61-73. doi: 10.1002/ wcs. 1266

4. Spreckelmeyer KN, Krach S, Kohls G, Rademacher L, Irmak A, Konrad K, et al. Anticipation of monetary and social reward differently activates mesolimbic brain structures in men and women. Soc Cognit Affect Neurosci (2009) 4:158-65. doi: 10.1093/scan/nsn051 social processes, another body of literature focuses on the similarities among different types of rewards (including social), suggesting that there is a common valuation network in the brain. These two lines of research seem contradictory: One argues that social and non-social rewards are different and the other suggests that they are the same. However, the proposed multidimensional view provides a simple integration (see also Murayama (34), in the context of the distinction between intrinsic and extrinsic rewards). While social and non-social rewards are both reinforcers with the potential to guide behavior, their differential effects are (at least in part) attributable to properties on other dimensions on which rewards can be described (e.g., temporal proximity, familiarity, etc.). Using the multidimensional view as a starting point, we can thoroughly reflect upon mechanisms underlying the processing of social rewards, being able to go beyond the simple assertion that social rewards and non-social rewards are either similar or different.

\section{AUTHOR CONTRIBUTIONS}

All authors contributed to the article and approved the submitted version.

\section{FUNDING}

This study was supported by funding from the Berlin School of Mind and Brain, Humboldt-Universität zu Berlin, the German Academic Exchange Service (Deutscher Akademischer Austauschdienst; DAAD), JSPS KAKENHI (16H06406, 18H01102, and 18K18696), the F. J. McGuigan Early Career Investigator Prize, the Jacobs Foundation Advanced Fellowship and the Leverhulme Trust (RL-2016-030).

\section{ACKNOWLEDGMENTS}

A preprint of this article was released at OSFPreprints (72).

5. Deci EL. Effects of externally mediated rewards on intrinsic motivation. J Pers Soc Psychol (1971) 18:105-15. doi: 10.1037/h0030644

6. Oumeziane BA, Schryer-Praga J, Foti D. "Why don't they 'like' me more?": Comparing the time courses of social and monetary reward processing. Neuropsychologia (2017) 107:48-59. doi: 10.1016/j.neuropsychologia.2017.11.001

7. Izuma K, Saito DN, Sadato N. Processing of Social and Monetary Rewards in the Human Striatum. Neuron (2008) 58:284-94. doi: 10.1016/j.neuron.2008.03.020

8. American Psychiatric Association. Diagnostic and statistical manual of mental disorders (5th ed.). Washington, DC: American Psychiatric Publishing, Inc., (2013). doi: 10.1176/appi.books.9780890425596

9. Chevallier C, Kohls G, Troiani V, Brodkin ES, Schultz RT. The social motivation theory of autism. Trends Cognit Sci (2012) 16:231-9. doi: 10.1016/j.tics.2012.02.007

10. Bottini S. Social reward processing in individuals with autism spectrum disorder: A systematic review of the social motivation hypothesis. RASD (2018) 45:9-26. doi: 10.1016/j.rasd.2017.10.001 
11. Kohls G, Peltzer J, Herpertz-Dahlmann B, Konrad K. Differential effects of social and non-social reward on response inhibition in children and adolescents. Dev Sci (2009) 12:614-25. doi: 10.1111/j.1467-7687.2009.00816.x

12. Von Neumann J, Morgenstern O. Theory of Games and Economic Behavior. Princeton, NJ: Princeton University Press (1944).

13. Thibaut JW, Kelley HH. The social psychology of groups. Milton Park, Abingdon, Oxfordshire, UK: Routledge (1959). doi: 10.4324/9781315135007

14. Haber SN, Knutson B. The reward circuit: Linking primate anatomy and human imaging. Neuropsychopharmacology (2010) 35:4-26. doi: 10.1038/ npp.2009.129

15. Ruff CC, Fehr E. The neurobiology of rewards and values in social decision making. Nat Rev Neurosci (2014) 15(8):549-62. doi: 10.1038/nrn3776

16. Wake SJ, Izuma K. A common neural code for social and monetary rewards in the human striatum. Soc Cognit Affect Neurosci (2017) 12:1558-64. doi: $10.1093 /$ scan/nsx092

17. Smith DV, Hayden BY, Truong T-K, Song AW, Platt ML, Huettel SA. Distinct Value Signals in Anterior and Posterior Ventromedial Prefrontal Cortex. J Neurosci (2010) 30:2490-5. doi: 10.1523/JNEUROSCI.3319-09.2010

18. Levy DJ, Glimcher PW. Comparing apples and oranges: Using reward-specific and reward-general subjective value representation in the brain. $J$ Neurosci (2011) 31:14693-707. doi: 10.1523/JNEUROSCI.2218-11.2011

19. Lin A, Adolphs R, Rangel A. Social and monetary reward learning engage overlapping neural substrates. Soc Cognit Affect Neurosci (2012) 7:274-81. doi: $10.1093 /$ scan/nsr006

20. Sescousse G, Redouté J, Dreher JC. The architecture of reward value coding in the human orbitofrontal cortex. J Neurosci (2010) 30:13095-104. doi: 10.1523/ JNEUROSCI.3501-10.2010

21. Galbin A. An Introductioin to Social Constructionism. Soc Res Rep (2014) 26:82-92.

22. Skinner BF. The behavior of organisms: An Experimental Analysis. D. Appleton-Century Company: New York, London (1938).

23. Delgado MR, Labouliere CD, Phelps EA. Fear of losing money? Aversive conditioning with secondary reinforcers. Soc Cognit Affect Neurosci (2006) 1:250-9. doi: 10.1093/scan/nsl025

24. Kim H, Shimojo S, O'Doherty JP. Overlapping responses for the expectation of juice and money rewards in human ventromedial prefrontal cortex. Cereb Cortex (2011) 21:769-76. doi: 10.1093/cercor/bhq145

25. Ballard K, Knutson B. Dissociable neural representations of future reward magnitude and delay during temporal discounting. Neuroimage (2009) 45:143-50. doi: 10.1016/j.neuroimage.2008.11.004

26. Bermudez MA, Schultz W. Timing in reward and decision processes. Philosophical Transactions of the Royal Society B: Biological Sciences (2014) 369(1637):20120468. doi: 10.1098/rstb.2012.0468

27. O’Doherty J, Kringelbach ML, Rolls ET, Hornak J, Andrews C. Abstract reward and punishment representations in the human orbitofrontal cortex. Neuroscience (2001) 4:95-102. doi: 10.1038/82959

28. Juechems K, Balaguer J, Ruz M, Summerfield C. Ventromedial Prefrontal Cortex Encodes a Latent Estimate of Cumulative Reward. Neuron (2017) 93:705-714.e4. doi: 10.1016/j.neuron.2016.12.038

29. Guitart-Masip M, Bunzeck N, Stephan KE, Dolan RJ, Duzel E. Contextual Novelty Changes Reward Representations in the Striatum. J Neurosci (2010) 30:1721-6. doi: 10.1523/JNEUROSCI.5331-09.2010

30. Pankert A, Pankert K, Herpertz-Dahlmann B, Konrad K, Kohls G. Responsivity to familiar versus unfamiliar social reward in children with autism. J Neural Transm (2014) 121:1199-210. doi: 10.1007/s00702-014-1210-6

31. Ramon M, Gobbini MI. Familiarity matters: A review on prioritized processing of personally familiar faces. Vis Cognit (2018) 26:179-95. doi: 10.1080/13506285.2017.1405134

32. Liccione D, Moruzzi S, Rossi F, Manganaro A, Porta M, Nugrahaningsih N, et al. Familiarity is not notoriety: phenomenological accounts of face recognition. Front Hum Neurosci (2014) 8:672:672. doi: 10.3389/ fnhum.2014.00672

33. Deci EL, Ryan RM. Extrinsic Rewards and Intrinsic Motivation in Education: Reconsidered Once Again. Rev Educ Res (2001) 71:1-27. doi: 10.3102/ 00346543071001001

34. Murayama K. Neuroscientific and Psychological Approaches to Incentives: Commonality and Multifaceted Views. In: Renninger K, Hidi S, editors. The Cambridge Handbook of Motivation and Learning. Cambridge: University
Press. (2019) p. 141-62. https://www.ceeol.com/search/article-detail?id= 161941.

35. Lee W. Insular cortex activity as the neural base of intrinsic motivation. In: Kim S-I, Reeve J, Bong M, editors. Advances in Motivation and Achievement. Bingley, UK: Emerald Group Publishing Ltd. (2016). p. 127-48. doi: 10.1108/ S0749-742320160000019016

36. Yoon HJ, Sung SY, Choi JN, Lee K, Kim S. Tangible and Intangible Rewards and Employee Creativity: The Mediating Role of Situational Extrinsic Motivation. Creat Res J (2015) 27:383-93. doi: 10.1080/10400419.2015.1088283

37. Deci EL, Ryan RM. Koestner R. A meta-analytic review of experiments examining the effects of extrinsic rewards on intrinsic motivation. Psychol Bull (1999) 125:627-68. doi: 10.1037/0033-2909.125.6.627

38. Albrecht K, Abeler J, Weber B, Falk A. The brain correlates of the effects of monetary and verbal rewards on intrinsic motivation. Front Neurosci (2014) 8:303. doi: 10.3389/fnins.2014.00303

39. Warneken F, Tomasello M. Extrinsic Rewards Undermine Altruistic Tendencies in 20-Month-Olds. Dev Psychol (2008) 44:1785-8. doi: 10.1037/ a0013860

40. Kim K, Rosenthal MZ, Gwaltney M, Jarrold W, Hatt N, McIntyre N, et al. A Virtual Joy-Stick Study of Emotional Responses and Social Motivation in Children with Autism Spectrum Disorder. J Autism Dev Disord (2015) 45:3891-9. doi: 10.1007/s10803-014-2036-7

41. Gonzalez-Gadea ML, Sigman M, Rattazzi A, Lavin C, Rivera-Rei A, Marino J, et al. Neural markers of social and monetary rewards in children with Attention-Deficit/Hyperactivity Disorder and Autism Spectrum Disorder. Sci Rep (2016) 6:30588. doi: 10.1038/srep30588

42. Kätsyri J, de Gelder B, de Borst AW. Amygdala responds to direct gaze in real but not in computer-generated faces. Neuroimage (2020) 204:116216. doi: 10.1016/j.neuroimage.2019.116216

43. Knutson B, Adams CM, Fong GW, Hommer D. Anticipation of increasing monetary reward selectively recruits nucleus accumbens. J Neurosci (2001) 21:1-5. doi: 10.1523/jneurosci.21-16-j0002.2001

44. Smith BW, Mitchell DGV, Hardin MG, Jazbec S, Fridberg D, Blair RJR, et al. Neural substrates of reward magnitude, probability, and risk during a wheel of fortune decision-making task. Neuroimage (2009) 44:600-9. doi: 10.1016/ j.neuroimage.2008.08.016

45. Diekhof EK, Kaps L, Falkai P, Gruber O. The role of the human ventral striatum and the medial orbitofrontal cortex in the representation of reward magnitude - An activation likelihood estimation meta-analysis of neuroimaging studies of passive reward expectancy and outcome processing. Neuropsychologia (2012) 50:1252-66. doi: 10.1016/ j.neuropsychologia.2012.02.007

46. Dai Q, Wei J, Shu X, Feng Z. Negativity bias for sad faces in depression: An event-related potential study. Clin Neurophysiol (2016) 127:3552-60. doi: 10.1016/J.CLINPH.2016.10.003

47. Cox A, Kohls G, Naples AJ, Mukerji CE, Coffman MC, Rutherford HJV, et al. Diminished social reward anticipation in the broad autism phenotype as revealed by event-related brain potentials. Soc Cognit Affect Neurosci (2015) 10:1357-64. doi: 10.1093/scan/nsv024

48. Cremers HR, Veer IM, Spinhoven P, Rombouts SARB, Roelofs K. Neural sensitivity to social reward and punishment anticipation in social anxiety disorder. Front Behav Neurosci (2015) 8:439. doi: 10.3389/fnbeh.2014.00439

49. Ethridge P, Kujawa A, Dirks MA, Arfer KB, Kessel EM, Klein DN, et al. Neural responses to social and monetary reward in early adolescence and emerging adulthood. Psychophysiology (2017) 54:1786-99. doi: 10.1111/psyp.12957

50. Pfabigan DM, Gittenberger M, Lamm C. Social dimension and complexity differentially influence brain responses during feedback processing. Soc Neurosci (2017) 14:26-40. doi: 10.1080/17470919.2017.1395765

51. Krach S, Paulus FM, Bodden M. Kircher Ti. The rewarding nature of social interactions. Front Behav Neurosci (2010) 4:22:22. doi: 10.3389/fnbeh. 2010.00022

52. Pfabigan DM, Han S. Converging electrophysiological evidence for a processing advantage of social over nonsocial feedback. Cognit Affect Behav Neurosci (2019) Springer, Cham. 19:1170-83. doi: 10.3758/s13415-01900737-9

53. Kujawa A, Arfer KB, Klein DN, Proudfit GH. Electrocortical reactivity to social feedback in youth: A pilot study of the Island Getaway task. Dev Cognit Neurosci (2014) 10:140-7. doi: 10.1016/J.DCN.2014.08.008 
54. Saxe R, Haushofer J. For Love or Money: A Common Neural Currency for Social and Monetary Reward. Neuron (2008) 58:164-5. doi: 10.1016/ J.NEURON.2008.04.005

55. Hasson U, Nir Y, Levy I, Fuhrmann G, Malach R. Intersubject Synchronisation of Cortical Activity During Natural Vision. Sci (80- ) (2004) 303:1634-40. doi: 10.1126/science.1089506

56. Dziobek I. Towards a More Ecologically Valid Assessment of Empathy. Emot Rev (2012) 4:18-9. doi: 10.1177/1754073911421390

57. Schilbach L, Timmermans B, Reddy V, Costall A, Bente G, Schlicht T, et al. Toward a second-person neuroscience. Behav Brain Sci (2013) 36:393-414. doi: 10.1017/S0140525X12000660

58. Drimalla H, Landwehr N, Baskow I, Behnia B, Roepke S , Dziobek I, et al. Detecting Autism by Analyzing a Simulated Social Interaction. In: Joint European Conference on Machine Learning and Knowledge Discovery in Databases. Springer, Cham (2018). p. 193-208.

59. Kohls G, Peltzer J, Schulte-Rüther M, Kamp-Becker I, Remschmidt H, Herpertz-Dahlmann B, et al. Atypical brain responses to reward cues in autism as revealed by event-related potentials. J Autism Dev Disord (2011) 41:1523-2533. doi: 10.1007/s10803-011-1177-1

60. Kohls G, Schulte-Rüther M, Nehrkorn B, Müller K, Fink GR, Kamp-Becker I, et al. Reward system dysfunction in autism spectrum disorders. Soc Cognit Affect Neurosci (2013) 8:565-72. doi: 10.1093/scan/nss033

61. Richey JA, Rittenberg A, Hughes L, Damiano CR, Sabatino A, Miller S, et al. Common and distinct neural features of social and non-social reward processing in autism and social anxiety disorder. Soc Cognit Affect Neurosci (2014) 9:367-77. doi: 10.1093/scan/nss146

62. Kohls G, Antezana L, Mosner MG, Schultz RT, Yerys BE. Altered reward system reactivity for personalized circumscribed interests in autism. Mol Autism (2018) 9. doi: 10.1186/s13229-018-0195-7

63. Farroni T, Menon E, Rigato S, Johnson MH. The perception of facial expressions in newborns. Eur J Dev Psychol (2007) 4:2-13. doi: 10.1080/17405620601046832

64. O’Doherty J, Rolls ET, Francis S, Bowtell R, McGlone F, Kobal G, et al. Sensoryspecific satiety-related olfactory activation of the human orbitofrontal cortex. NeuroReport (2000) 11(4):893-97. doi: 10.1097/00001756-200003200-00046

65. Bragulat V, Dzemidzic M, Bruno C, Cox CA, Talavage T, Considine RV, et al. Food-related odor probes of brain reward circuits during hunger: a pilot FMRI study. Obesity (Silver Spring, Md.) (2010) 18(8):1566-71. doi: 10.1038/ oby. 2010.57

66. Jiang T, Soussignan R, Schaal B, Royet JP. Reward for food odors: An fMRI study of liking and wanting as a function of metabolic state and BMI. Soc Cogn Affect Neurosci (2015) 10(4):561-8. doi: 10.1093/scan/nsu086

67. Lehner R, Balsters JH, Herger A, Hare TA, Wenderoth N. Monetary, food, and social rewards induce similar pavlovian-to-instrumental transfer effects. Front Behav Neurosci (2017) 1-12. doi: 10.3389/fnbeh.2016.00247

68. Knutson B, Westdorp A, Kaiser E, Hommer D. FMRI visualization of brain activity during a monetary incentive delay task. Neuroimage (2000) 12:20-7. doi: 10.1006/nimg.2000.0593

69. Rademacher L, Krach S, Kohls G, Irmak A, Gründer G, Spreckelmeyer KN. Dissociation of neural networks for anticipation and consumption of monetary and social rewards. Neuroimage (2010) 49:3276-85. doi: 10.1016/ j.neuroimage.2009.10.089

70. Liu X, Hairston J, Schrier M, Fan J. Common and distinct networks underlying reward valence and processing stages: A meta-analysis of functional neuroimaging studies. Neurosci Biobehav Rev (2011) 35:1219-36. doi: 10.1016/j.neubiorev.2010.12.012

71. Matyjek M, Bayer M, Dziobek I. Autistic Traits Affect Reward Anticipation but not Reception. Sci Rep (2020) 10:8396. doi: 10.1038/s41598-020-65345-x

72. Matyjek M, Meliss S, Dziobek I, Murayama K. A Multidimensional View on Social and Non-social Rewards. OSF Preprints (2020). doi: 10.31219/osf.io/ gjfr5

Conflict of Interest: The authors declare that the research was conducted in the absence of any commercial or financial relationships that could be construed as a potential conflict of interest.

Copyright (C) 2020 Matyjek, Meliss, Dziobek and Murayama. This is an open-access article distributed under the terms of the Creative Commons Attribution License (CC BY). The use, distribution or reproduction in other forums is permitted, provided the original author(s) and the copyright owner(s) are credited and that the original publication in this journal is cited, in accordance with accepted academic practice. No use, distribution or reproduction is permitted which does not comply with these terms. 